\title{
Effect of Carbon Source and pH on the Production and Secretion of Acid Phosphatase (EC 3.1.3.2) and Alkaline Phosphatase (EC 3.1.3.1) in Neurospora crassa
}

\author{
By ELY NAHAS, † HÉCTOR F. TERENZI AND ANTONIO ROSSI* \\ Departamento de Química, FFCLRP-USP, 14.100 Ribeirão Preto, SP, Brazil
}

(Received 15 September 1981; revised 17 January 1982)

\begin{abstract}
Growth conditions (carbon source and $\mathrm{pH}$ of the medium) affected the level and distribution of derepressed acid and alkaline phosphatases in Neurospora crassa. Regardless of the $\mathrm{pH}$, the production of both acid and alkaline phosphatases was stimulated by sucrose. Irrespective of the carbon source used, at $\mathrm{pH}$ values higher than 7.4 the secretion of alkaline phosphatase was stimulated, while the production and secretion of acid phosphatase was restricted. The converse was true at $\mathrm{pH}$ values lower than 5.7 . The secretion of one of these enzymes did not exclude the simultaneous secretion of the other at $\mathrm{pH}$ values of around $7 \cdot 0$. These results suggest that the $\mathrm{pH}$ of the medium may play an important role in the survival of the organism in phosphorus-limited environments.
\end{abstract}

\section{INTRODUCTION}

Neurospora crassa derepresses a number of phosphate-metabolizing enzymes during phosphate starvation, or mycelial growth on limiting concentrations of phosphate (Nyc et al., 1966; Nyc, 1967; Kadner et al., 1968; Lehman et al., 1973; Hasunuma, 1973; Burton \& Metzenberg, 1974; Hasunuma et al., 1976). Under these conditions a wild-type strain secretes a significant fraction of the acid phosphatase produced into the growth medium, and retains most of the alkaline phosphatase in a cell-bound form (Kadner et al., 1968; Lehman et al., 1973; Hasunuma, 1973; Hasunuma \& Ishikawa, 1977). The production of these two enzymes is reported to be regulated by the same derepression mechanism (Littlewood et al., 1975; Metzenberg, 1979). However, the relative levels of these enzymes and their secretion into the growth medium could also be controlled by additional physiological factors. With this in mind, we investigated further the derepression and secretion of these two enzymes by $N$. crassa mycelium. Our results suggest that, besides the derepression by phosphate starvation, the carbon source used for growing the cells influences the level of phosphatase production and that, for a specified carbon source, the production and secretion of these two enzymes is dependent on the $\mathrm{pH}$ of the growth medium.

\section{METHODS}

Chemicals. 4-Nitrophenyl disodium orthophosphate (PNP-P) was purchased from Merck. All other chemicals were of analytical reagent grade.

Strains and maintenance of organisms. The following strains of $N$. crassa were used; wild-type strain St.L. 74A, the nuc-1 A mutant FGSC 1995, the nuc-2 A mutant FGSC 1996 and the pho-2 A mutant FGSC 3061. Stock cultures were maintained on slants of semi-solid Vogel's (1956) medium.

Growth conditions and preparation of cell extracts. Conidia from each strain were suspended in sterilized

† Present address: Departamento de Microbiologia, FCAVJ-UNESP, 14.780 Jaboticabal, SP, Brazil.

† Present address: Departamento de Fisiologia, FMRP-USP, 14.100 Ribeirão Preto, SP, Brazil. 
deionized water and filtered with a double layer of gauze to remove contaminating mycelia. Conidial suspensions were adjusted to $10^{8}$ cells $\mathrm{ml}^{-1}$. Unless otherwise mentioned, $0.5 \mathrm{ml}$ of this conidial suspension was inoculated into each Petri dish (14 cm diameter), containing $50 \mathrm{ml}$ low-phosphate medium (adjusted to $\mathrm{pH} 5.6$ ) prepared as previously described (Crocken \& Nyc, 1963). After a period of growth the mycelium was harvested by filtration, washed with distilled water and pressed to remove excess liquid. It was then ground in a pre-cooled mortar with washed sand and $50 \mathrm{~mm}$-sodium acetate buffer, $\mathrm{pH} 5.0$ [40 $\mathrm{ml}$ buffer ( $\mathrm{g}$ mycelium $\left.)^{-1}\right]$. The mycelial extract was centrifuged at $20000 \mathrm{~g}$ for $20 \mathrm{~min}$, at $4^{\circ} \mathrm{C}$, and the supernatant used for enzyme assays without further treatment.

Enzyme assays. The repressible acid phosphatase assay was carried out in $0.1 \mathrm{M}$-sodium acetate buffer (pH 5.4), using $2 \mathrm{ml} 6 \mathrm{~mm}$-PNP-P as substrate, at $37^{\circ} \mathrm{C}$. The reaction was stopped by the addition of $1 \mathrm{ml} 1 \mathrm{M}-\mathrm{NaOH}$, and the $p$-nitrophenoxide ion absorbance measured at $405 \mathrm{~nm}\left(\varepsilon=178001 \mathrm{~mol}^{-1} \mathrm{~cm}^{-1}\right)$. The repressible alkaline phosphatase assay was carried out in $0.3 \mathrm{M}$-glycine buffer ( $\mathrm{pH} \mathrm{9.0)}$ containing $1 \mathrm{~mm}$-EDTA, using the same procedure as for acid phosphatase (Nyc et al., 1966). Both enzyme activities were assayed in the culture filtrate and the cell extracts. One unit of phosphatase activity was defined as $1 \mu \mathrm{mol}$ substrate hydrolysed $\mathrm{h}^{-1}$. Specific activities were expressed as units (mg dry wt mycelium) $)^{-1}$.

\section{RESULTS AND DISCUSSION}

The production of acid and alkaline phosphatase by $N$. crassa when grown on sucrose is shown in Fig. 1. Confirming earlier reports (Nyc, 1967), the production of acid phosphatase was stimulated, with a significant fraction of this enzyme being secreted into the growth medium. It can also be seen that the production of alkaline phosphatase was stimulated and that most of its activity was present in the mycelial extract. When the organism was grown on acetate, the production of acid and alkaline phosphatase was, respectively, $17 \%$ and $160 \%$ of that obtained in sucrose-grown cultures (Table 1). Moreover, about $40 \%$ of the alkaline phosphatase produced by the fungus in acetate cultures was secreted into the growth medium. It was previously reported (Hasunuma \& Ishikawa, 1977) that when a wild-type strain of $N$. crassa was grown on sucrose, a significant fraction of the alkaline phosphatase produced was secreted into the growth medium. Our results show that only about $5 \%$ of the alkaline phosphatase produced by the fungus on sucrose cultures was secreted into the growth medium (Fig. 1). However, after growth on acetate the secretion of this enzyme was enhanced about 10 -fold (Table 1). When $N$. crassa was grown on glycerol the production of acid and alkaline phosphatase was only $25 \%$ of that found when it was grown on sucrose. It was also observed that the relationship between production and secretion of these enzymes was similar to that obtained for the sucrose-grown cultures (data not shown). The $\mathrm{pH}$ of the medium remained almost constant during mycelial growth on sucrose (inset Fig. 1) and glycerol (data not shown) while during growth on acetate the $\mathrm{pH}$ increased, reaching 8.8 after $72 \mathrm{~h}$ incubation (Table 1). When the fungus was grown on a mixture of acetate and variable concentrations of sucrose, the production and secretion of acid phosphatase was stimulated by sucrose (Fig. 2). Nevertheless, the production and secretion of this enzyme was lower than that obtained for cultures grown on sucrose alone (Fig. 1). The production of alkaline phosphatase was also stimulated by sucrose in combination with acetate (Fig. 2). However, this was only observed for the mycelial-bound enzyme. It can also be seen that, after growth for $72 \mathrm{~h}$ on acetate/sucrose $(44 \mathrm{~mm})$, the $\mathrm{pH}$ was about two units lower than after growth on acetate alone (inset Fig. 2). From the results presented above it might be supposed that the pattern of derepression of acid and alkaline phosphatase by mycelium is affected by (apart from phosphate starvation) variations in the $\mathrm{pH}$ and/or by the carbon source used for growing the cells.

For a further understanding of the effects of carbon source and $\mathrm{pH}$ on the production and secretion of acid and alkaline phosphatases, the wild-type strain of $N$. crassa was grown on sucrose and acetate, buffered with $50 \mathrm{mM}$-Tris/ $\mathrm{HCl}$ at $\mathrm{pH} 7.5$ and with $100 \mathrm{~mm}$-sodium

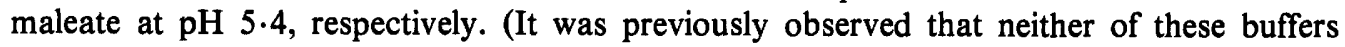
could be utilized by the fungus as carbon or nitrogen sources.) From the results in Table 1 it is clear that the production and secretion of alkaline phosphatase was stimulated by the increase in the $\mathrm{pH}$ of the sucrose cultures. The results also show that the secretion of acid 


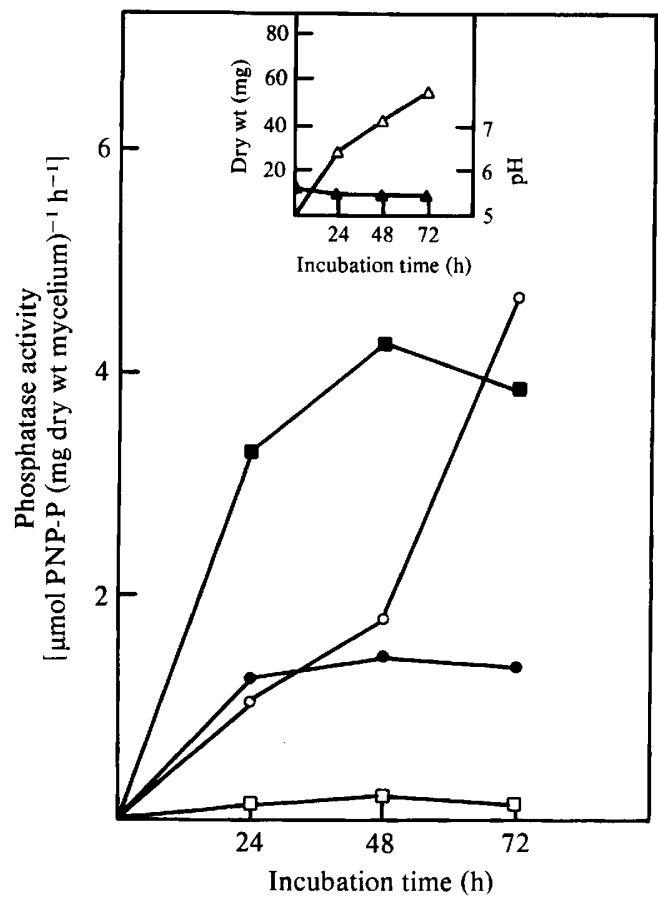

Fig. 1. Production of acid and alkaline phosphatases in cultures of $N$. crassa (St.L. 74A) grown on sucrose $(44 \mathrm{mM})$ under limiting phosphate conditions $(50 \mu \mathrm{M})$, at $30^{\circ} \mathrm{C}$. $\mathrm{O}$, Mycelial-bound acid phosphatase; $O$, extracellular acid phosphatase; $\square$, mycelial-bound alkaline phosphatase; $\square$, extracellular alkaline phosphatase. Inset: $\Delta$, dry weight of mycelial yield (mg per $50 \mathrm{ml}$ medium); $\boldsymbol{\Delta}, \mathrm{pH}$ of medium. See Methods for details.

Table 1. Activity of acid and alkaline phosphatases in cultures of N. crassa (St.L. 74A) grown under different conditions for $72 \mathrm{~h}$

$\begin{array}{cccccccc}\begin{array}{c}\text { Carbon source } \\ \text { and medium conditions }\end{array} & \begin{array}{c}\text { Final pH } \\ \text { of medium }\end{array} & \overbrace{\begin{array}{c}\text { Mycelial } \\ \text { extract }\end{array}}^{\text {Acid phosphatase* }} \begin{array}{c}\text { Culture } \\ \text { medium }\end{array} & \text { Total } & \begin{array}{c}\text { Mycelial } \\ \text { extract }\end{array} & \begin{array}{c}\text { Culture } \\ \text { medium }\end{array} & \text { Total } \\ \begin{array}{c}\text { Sucrose } \\ \text { (non-buffered medium) }\end{array} & 5.6 & 1.4 & 4.7 & 6.1 & 3.9 & 0.2 & 4.1 \\ \begin{array}{c}\text { Sucrose } \\ \text { (buffered medium) }\end{array} & 7.5 & 1.0 & 1.0 & 2.0 & 10.5 & 5.3 & 15.8 \\ \begin{array}{c}\text { Sucrose + acetate } \\ \text { (non-buffered medium) }\end{array} & 6.9 & 2.0 & 2.0 & 4.0 & 11.3 & 3.2 & 14.5 \\ \begin{array}{c}\text { Acetate } \\ \text { (non-buffered medium) }\end{array} & 8.8 & 0.6 & 0.4 & 1.0 & 4.0 & 2.6 & 6.6 \\ \begin{array}{c}\text { Acetate } \\ \text { (buffered medium) }\end{array} & 5.4 & 0.8 & 1.5 & 2.3 & 2.5 & 0.3 & 2.8 \\ & * \text { Units (mg dry wt mycelium) } & & & & & \end{array}$

phosphatase was significantly reduced, with the cell-bound enzyme level remaining close to that obtained from the non-buffered sucrose cultures (Fig. 1). In contrast, when $N$. crassa was grown on buffered acetate media (pH 5.4), the secretion of alkaline phosphatase was significantly reduced, the intracellular enzyme level also being lowered (Table 1). Furthermore, the production of acid phosphatase was stimulated, and most of this enzyme activity was secreted into the growth medium. The same phenomena were observed when the mycelium harvested from cultures grown on high-phosphate supplemented media ( $3 \mathrm{~d}$ old), 


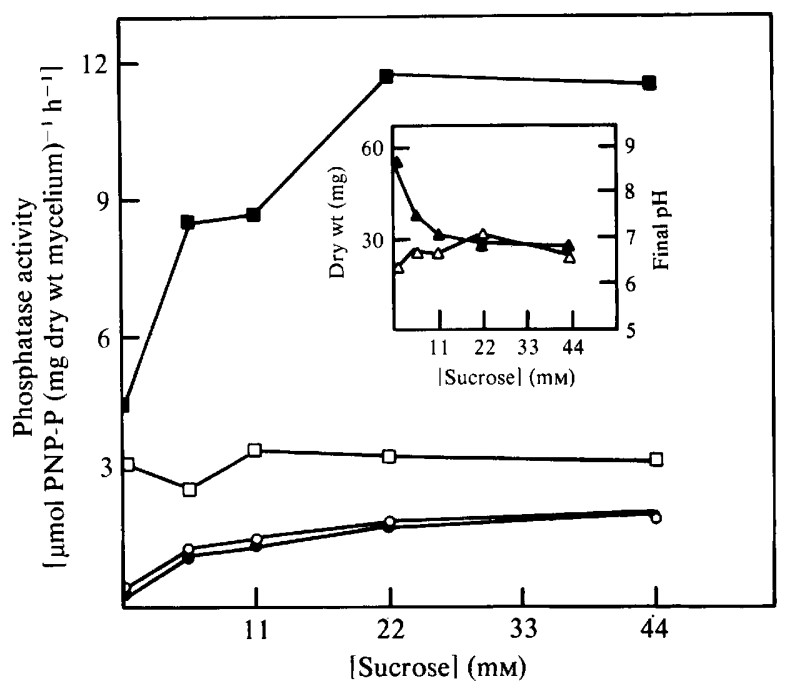

Fig. 2. Final specific activity of acid and alkaline phosphatases in cultures of $N$. crassa (St.L. 74A) grown on acetate (44 mM) and mixtures of acetate $(44 \mathrm{~mm})$ and sucrose $(11,22$ and $44 \mathrm{~mm})$, under limiting phosphate conditions $(50 \mu \mathrm{M})$, at $30^{\circ} \mathrm{C}$ for $72 \mathrm{~h}$. $\mathrm{O}$, Mycelial-bound acid phosphatase; $\boldsymbol{O}$, extracellular acid phosphatase; $\mathbf{\square}$, mycelial-bound alkaline phosphatase; $\square$, extracellular alkaline phosphatase. Inset: $\Delta$, dry weight of mycelial yield (mg per $50 \mathrm{ml}$ medium); $\boldsymbol{\Delta}$, final $\mathrm{pH}$ of medium. See text for details.

was re-incubated in all conditions of phosphate starvation described in this paper (data not shown).

The secretion of alkaline phosphatase as a consequence of possible structural changes of the cell membrane during growth on acetate can be excluded, since this enzyme was not secreted by the fungus when grown on acetate buffered at $\mathrm{pH} 5.4$ (Table 1). Cell lysis may also be ruled out, because the secretion of alkaline phosphatase was observed in the growing phase of mycelia.

The data presented in this report show that, regardless of the $\mathrm{pH}$, the production of both acid and alkaline phosphatase was stimulated by sucrose. On the other hand, irrespective of the carbon source used, the $\mathrm{pH}$ seems to represent an important physiological factor which selectively affected the secretion of one of these two enzymes. Thus, at $\mathrm{pH}$ values lower than 5.7 (non-buffered sucrose and buffered acetate media) most of the derepressed acid phosphatase was secreted into the growth medium by the fungus. Under these conditions, only a small fraction of the alkaline phosphatase produced was secreted by the wild-type strain. At pH values close to 7.0 (buffered sucrose and non-buffered sucrose/acetate media) significant fractions of both enzymes were secreted by the fungus, the secretion of alkaline phosphatase being predominant. At $\mathrm{pH}$ values close to 9.0 (non-buffered acetate medium) the production and secretion of acid phosphatase was more restricted, and about $40 \%$ of the alkaline phosphatase produced was secreted into the growth medium. The production and secretion of alkaline phosphatase by mycelium grown on non-buffered acetate or buffered sucrose medium was investigated in the regulatory mutants nuc-1 and nuc-2. These mutants do not derepress a number of enzymes associated with phosphorus assimilation, including acid and alkaline phosphatase (Littlewood et al., 1975). These mutants produced less than 0.1 unit of alkaline phosphatase (mg dry weight) ${ }^{-1}$ under all conditions specified in this paper. Similarly, in the pho-2 mutant, which is considered to represent the structural locus of the repressible alkaline phosphatase (Lehman \& Metzenberg, 1976), the production of this enzyme was negligible. Thus, it appears that the effects of $\mathrm{pH}$ and the carbon source involved the participation of the regulatory circuit already proposed (Metzenberg, 1979), and that the secreted alkaline phosphatase and that retained by the mycelium when the wild-type strain 
was grown on acetate and sucrose, respectively, were the product of the pho- 2 gene. However, they may differ in the degree of post-translational modification, as already noted for the alkaline phosphatase secreted by 'slime' cells (Burton \& Metzenberg, 1974).

From these results it is clear that the pattern of secretion of derepressed acid and alkaline phosphatase is affected by the $\mathrm{pH}$ of the medium. This property may be of physiological significance for the survival of the organism in a phosphorus-limited environment.

This work was supported by the Conselho Nacional de Desenvolvimento Cientifico e Tecnológico (Grant no. 40.3107/79).

\section{REFERENCES}

Burton, E. G. \& Metzenberg, R. L. (1974). Properties of repressible alkaline phosphatase from wild type and a wall-less mutant of Neurospora crassa. Journal of Biological Chemistry 249, 46794688.

Crocken, B. \& Nyc, J. F. (1963). Utilization of L-a-glycerophosphorylcholine by a lecithin-deficient strain of Neurospora crassa. Canadian Journal of Microbiology 9, 689-696.

Hasunuma, K. (1973). Repressible extracellular nucleases in Neurospora crassa. Biochimica et biophysica acta 319, 288-293.

Hasunuma, K. \& Ishikawa, T. (1977). Control of the production and partial characterization of repressible extracellular 5'-nucleotidase and alkaline phosphatase in Neurospora crassa. Biochimica et biophysica acta 480, 178-193.

Hasunuma, K., Toh-E. A. \& Ishikawa, T. (1976). Control of the formation of extracellular ribonuclease in Neurospora crassa. Biochimica et biophysica acta 432, 223-236.

KADNER, R. J., Nyc, J. F. \& Brown, D. M. (1968). A repressible alkaline phosphatase in Neurospora crassa. II. Isolation and chemical properties. Journal of Biological Chemistry 243, 3076-3082.
Lehman, J. F. \& Metzenberg, R. L. (1976). Regulation of phosphate metabolism in Neurospora crassa: identification of the structural gene for repressible alkaline phosphatase. Genetics 84, 175182.

Lehman, J. F., Gleason, M. K., Ahlgren, S. K. \& MetzenberG, R. L. (1973). Regulation of phosphate metabolism in Neurospora crassa. Genetics 75, 61-73.

Littlewood, B. S., Chia, W. \& Metzenberg, R. L. (1975). Genetic control of phosphate-metabolizing enzymes in Neurospora crassa: relationships among regulatory mutations. Genetics 79, 419-434.

METZENBERG, R. L. (1979). Implications of some genetic control mechanism in Neurospora. Microbiological Reviews 43, 361-383.

NyC, J. F. (1967). A repressible acid phosphatase in Neurospora crassa. Biochemical and Biophysical Research Communications 27, 183-188.

Nyc, J. F., KADNER, R. J. \& CROCKEN, B. J. (1966). A repressible alkaline phosphatase in Neurospora crassa. Journal of Biological Chemistry 241, 14681472.

VoGEL, H. J. (1956). A convenient growth medium for Neurospora. Microbial Genetics Bulletin 13, 42-43. 